Braz J Med Biol Res, October 2011, Volume 44(10) 1006-1012

doi: 10.1590/S0100-879X2011007500097

\section{Education, tobacco smoking, alcohol consumption, and IL-2 and IL- 6 gene polymorphisms in the survival of head and neck cancer}

\author{
R.V.M. López, M.A. Zago, J. Eluf-Neto, M.P. Curado, A.W. Daudt, W.A. da Silva-Junior, \\ D.L. Zanette, J.E. Levi, M.B. de Carvalho, L.P. Kowalski, M. Abrahão, J.F. de Góis-Filho, \\ P. Boffetta and V. Wünsch-Filho
}

The Brazilian Journal of Medical and Biological Research is partially financed by

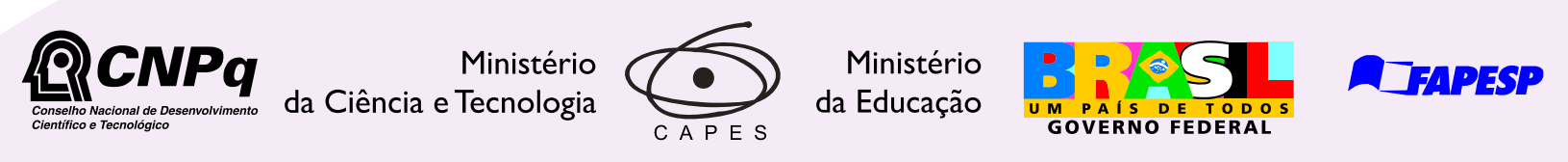

Institutional Sponsors
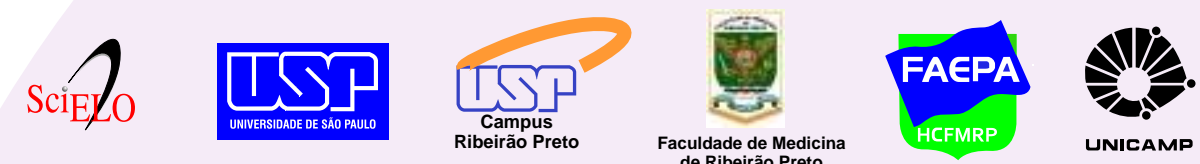

UNICAMP

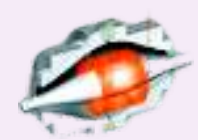

Explore High - Performance MS Orbitrap Technology In Proteomics \& Metabolomics

$\underset{\text { analitica }}{\text { analiticaweb.com.br }}$ SCIENTIFIC 


\title{
Education, tobacco smoking, alcohol consumption, and IL-2 and IL-6 gene polymorphisms in the survival of head and neck cancer
}

\author{
R.V.M. López¹, M.A. Zago², J. Eluf-Neto³, M.P. Curado4,5, A.W. Daudt6, W.A. da Silva-Junior², \\ D.L. Zanette ${ }^{2}$, J.E. Levi ${ }^{7}$, M.B. de Carvalho ${ }^{8}$, L.P. Kowalski ${ }^{9}$, M. Abrahão ${ }^{10}$, \\ J.F. de Góis-Filho ${ }^{11}$, P. Boffetta ${ }^{12,13}$ and V. Wünsch-Filho'
}

${ }^{1}$ Departamento de Epidemiologia, Faculdade de Saúde Pública, Universidade de São Paulo, São Paulo, SP, Brasil 2Laboratório de Genética Molecular, Faculdade de Medicina de Ribeirão Preto, Universidade de São Paulo, Ribeirão Preto, SP, Brasil ${ }^{3}$ Departamento de Medicina Preventiva, Faculdade de Medicina, Universidade de São Paulo, São Paulo, SP, Brasil ${ }^{4}$ Hospital Araújo Jorge and Registro de Câncer de Base Populacional de Goiânia, Goiânia, GO, Brasil 5 International Agency for Research on Cancer, World Health Organization, Lyon, France ${ }^{6}$ Departamento de Oncologia, Hospital de Clínicas de Porto Alegre, Porto Alegre, RS, Brasil ${ }^{7}$ Laboratório de Virologia, Instituto de Medicina Tropical, Universidade de São Paulo, São Paulo, SP, Brasil ${ }^{8}$ Departamento de Cirurgia de Cabeça e Pescoço, Hospital Heliópolis, São Paulo, SP, Brasil ${ }^{9}$ Departamento de Cirurgia de Cabeça e Pescoço, Hospital do Câncer A.C. Camargo, São Paulo, SP, Brasil ${ }^{10}$ Departamento de Otorrinolaringologia e Distúrbios da Comunicação, Universidade Federal de São Paulo, São Paulo, SP, Brasil ${ }^{11}$ Departamento de Cirurgia de Cabeça e Pescoço, Instituto do Câncer Arnaldo Vieira de Carvalho, São Paulo, SP, Brasil ${ }^{12}$ The Tisch Cancer Institute, Mount Sinai School of Medicine, New York, NY, USA ${ }^{13}$ International Prevention Research Institute, Lyon, France

\begin{abstract}
The association of education, tobacco smoking, alcohol consumption, and interleukin-2 (IL-2 +114 and -384) and -6 (IL-6 -174) DNA polymorphisms with head and neck squamous cell carcinoma (HNSCC) was investigated in a cohort study of 445 subjects. IL-2 and IL- 6 genotypes were determined by real-time PCR. Cox regression was used to estimate hazard ratios (HR) and 95\% confidence intervals $(95 \% \mathrm{Cl})$ of disease-specific survival according to anatomical sites of the head and neck. Mean age was 56 years and most patients were males (87.6\%). Subjects with 5 or more years of schooling had better survival in larynx cancer. Smoking had no effect on HNSCC survival, but alcohol consumption had a statistically significant effect on larynx cancer. IL-2 gene $+114 \mathrm{G} / \mathrm{T}(\mathrm{HR}=0.52 ; 95 \% \mathrm{Cl}=0.15-1.81)$ and $\mathrm{T} / \mathrm{T}(\mathrm{HR}=0.22 ; 95 \% \mathrm{Cl}=0.02-3.19)$ genotypes were associated with better survival in hypopharynx cancer. IL-2 $+114 \mathrm{G} / \mathrm{T}$ was a predictor of poor survival in oral cavity/oropharynx cancer and larynx cancer $(\mathrm{HR}=1.32 ; 95 \% \mathrm{Cl}=0.61-2.85)$. IL-2 -384 G/T was associated with better survival in oral cavity/oropharynx cancer (HR $=0.80 ; 95 \% \mathrm{Cl}=0.45-1.42)$ and hypopharynx cancer $(\mathrm{HR}=0.68 ; 95 \% \mathrm{Cl}=0.21-2.20)$, but an inverse relationship was observed for larynx cancer. IL-6 -174 G/C was associated with better survival in hypopharynx cancer $(\mathrm{HR}=0.68 ; 95 \% \mathrm{Cl}=0.26-1.78)$ and larynx cancer $(\mathrm{HR}=0.93 ; 95 \% \mathrm{Cl}=0.42-2.07)$, and $\mathrm{C} / \mathrm{C}$ reduced mortality in larynx cancer. In general, our results are similar to previous reports on the value of education, smoking, alcohol consumption, and IL-2 and IL-6 genetic polymorphisms for the prognosis of HNSCC, but the risks due to these variables are small and estimates imprecise.
\end{abstract}

Key words: Smoking; Alcohol; Interleukin; Head and neck cancer; Cancer prognosis; Survival analysis

\section{Introduction}

Tumors of the oral cavity, pharynx and larynx, collectively defined as head and neck cancer, are a significant cause of morbidity and mortality, with over 500,000 new cases estimated for 2008 worldwide (1). Annually about
22,000 new cases are diagnosed in Brazil, the majority in the South and Southeast regions (2). Squamous cell carcinoma is the most frequent histological type. Prognosis varies according to anatomical subsites. The relative 5-year

Correspondence: R.V.M. López, Departamento de Epidemiologia, Faculdade de Saúde Pública, USP, Av. Dr. Arnaldo, 715, 01246-904 São Paulo, SP, Brasil. Fax: +55-11-3060-8677. E-mail: rossana@usp.br

Received December 27, 2010. Accepted July 27, 2011. Available online August 12, 2011. Published October 10, 2011. 
survival rate is around $50-70 \%$, considering all sites and clinical stages, and all forms of treatment (3). In Brazil, the 5 -year survival rate for oral and oropharyngeal cancer is still below $50 \%$ (4).

Prognostic factors, which have been examined in relation to head and neck cancer survival, include clinical tumor stage, patient education, tobacco smoking, and alcohol consumption (5-7). More recently, some genetic markers have been studied in relation to head and neck cancer survival, including gene polymorphisms related to invasion and metastasis, inflammation and DNA repair (8-10).

Interleukins (IL) are a type of cytokines, which are small secreted proteins related to the inflammation process and angiogenesis (11). IL-2 is an immunoregulatory cytokine and high serum levels of its receptor, sIL-2Ra, have been correlated with poor head and neck cancer survival and can be considered an independent prognostic biomarker in these tumors (12). IL-2 DNA polymorphisms have been recently associated with prostate tumor formation (13) and low risk of gastric cancer (14), but not with risk of chronic lymphocytic leukemia (15). Associations have also been identified between IL-6 DNA polymorphisms and the risk of colorectal, lung and oral cancer (16-18). However, investigations of the role of interleukins in cancer prognosis are rare. IL-2 +114 and -384, and IL-6 -174 were not associated with prognosis of gastric cardia or esophageal cancer (19). IL-6 -174 has been correlated with poor survival in breast, bladder, and prostate cancer (20-22).

In this study, we addressed the role of education, tobacco smoking, alcohol consumption, and IL-2 +114 and -384, and IL-6 -174 genetic polymorphisms in the prognosis of head and neck squamous cell carcinoma (HNSCC).

\section{Material and Methods}

From November 1998 to December 2002, 586 individuals diagnosed with HNSCC were recruited at eight hospitals from three cities in Brazil (São Paulo, Goiânia, and Porto Alegre) and were followed up until June 30, 2005. The study was approved by the Ethics Committee of each clinical center and written informed consent was obtained from all participants. All head and neck cancer cases were con- firmed by histology as squamous cell carcinoma. Using the 10 th revision of the International Classification of Diseases (ICD-10) (23), tumors were grouped into three categories, according to anatomical subsites, considering their distinct prognosis: oral cavity/oropharynx, hypopharynx, or larynx. The ICD-10 coding used for subsite classification was that used by Hashibe et al. (24): oral cavity/oropharynx (C00.3C00.9, C01.9, C02.0-C02.3, C02.4, C02.8, C02.9, C03.0, C03.1, C04.0, C04.1, C04.8, C04.9, C05.0, C05.1, C05.8, C05.9, C06.0-C06.2, C06.8, C06.9, C09.0, C09.1, C09.8, C09.9, C10.0-C10.4, C10.8, C10.9, C14.0, C14.2, and C14.8), hypopharynx (C12.9, C13.0-C13.2, C13.8, and C13.9), or larynx (C32.0-C32.3, C32.8, and C32.9).

Patient hospital records were reviewed to obtain additional information about tumor clinical stage and treatment, and patient vital status. Tumor clinical stage was classified according to the tumor-node-metastases system (TNM) (25) as clinical stage (CS) I to IV. As the effect of tumor clinical stage on head and neck cancer survival is well known, we only included patients with advanced clinical stages (CS III and IV). As a consequence, the sample size was restricted to 445 subjects.

Information on patient vital status was also assessed by linking to population mortality and cancer registry databases. Cause of death was validated through death certificates obtained from the São Paulo State Death Registry (for patients from São Paulo city) and from the Population Cancer Registry of Goiânia (for patients from Goiânia). In Porto Alegre, death certificates were included in hospital medical records; these were also the only source of patient vital status information at that center. Of the 445 individuals, 111 were alive and 267 had died by the end of the study, with 224 deaths being related to head and neck cancer, and 67 were lost during follow-up.

All patients underwent face-to-face interviews immediately after diagnosis by a trained interviewer who used a structured questionnaire to obtain information on variables, which could impact head and neck cancer survival, such as education, tobacco smoking, and alcohol consumption. Formal education was measured in years of schooling. Tobacco smoking was measured by calculating the average number of cigarette packs smoked per day multiplied

Table 1. Primers for interleukin polymorphism genotyping.

\begin{tabular}{llll}
\hline Gene/SNP position & \multicolumn{1}{c}{ Forward primer (5'-3') } & \multicolumn{1}{c}{ Reverse primer (5'-3') } \\
\hline IL-2 +114 & Primers & 5'-GCACCTACTTCAAGTTCTACAAAGAA-3' & 5'-AAAGGAAATATACTTACATTAATTCCATTCAAAATCATCTG-3' \\
rs 2069763 & Probes & 5'-ATCCAGCAGTAAATG-3' & 5'-TAAATCCAGAAGTAAATG-3' \\
IL-2 -384 & Primers & 5'-GCTCTTGTCCACCACAATATGCTAT-3' & 5'-GCCTTCTGTATGAAACAGTTTTTCCT-3' \\
rs 2069762 & Probes & 5'-ATTTTCTTTGTCATAAAACT-3' & 5'-TTTCTTTGTCCTAAAACT-3' \\
IL-6 - 174 & Primers & 5'-GACGACCTAAGCTGCACTTTTC-3' & 5'-GGGCTGATTGGAAACCTTATTAAGATTG-3' \\
rs 1800795 & Probes & 5'-CTTTAGCATGGCAAGAC-3' & 5'-CTTTAGCATCGCAAGAC-3' \\
\hline
\end{tabular}

Source: Ref. 19. 
by the number of years smoking (pack-years) (26). Alcohol consumption prior to head and neck cancer diagnosis was measured in grams of ethanol per milliliter per day (g ethanol/day), considering the equivalence of ethanol in different beverages: beer, wine, and spirits (27).

Blood DNA was extracted at the Institute of Tropical Medicine, University of São Paulo, using the Qiagen kit ${ }^{\mathrm{TM}}$ and genotyping procedures were conducted at the Cell Therapy Center Faculty of Medicine of Ribeirão Preto, University of São Paulo. Genetic polymorphisms were determined by real-time polymerase chain reaction (PCR) using TaqMan SNP genotyping assays. These assays included two locus-specific PCR primers that flank the single nucleotide polymorphism (SNP) of interest, and two allele-specific oligonucleotide TaqMan $^{\circledR}$ probes (Applied Biosystems, USA). Each probe used a different fluorescent reporter dye at the 5 ' end, and a non-fluorescent quencher with a minor groove binder (MGB) at the 3' end. PCR primers amplify a specific locus on the genomic DNA template, and each fluorescent dye-labeled hybridization probe reports the presence of its associated allele in the DNA sample, as an allele-specific PCR, in a single tube (28). The primer design is unique and specific for the SNP, as assays are functionally tested against a small subset of genomic DNA by the supplier. All primers and probes were designed using the Assay-by-Design service offered by Applied Biosystems. These primers and probes are designed to be amplified under the following universal cycling conditions: $10 \mathrm{~min}$ at $95^{\circ} \mathrm{C}$, followed by 40 cycles of $94^{\circ} \mathrm{C}$ for $15 \mathrm{~s}$ and $60^{\circ} \mathrm{C}$ for $1 \mathrm{~min}$. All primers are depicted in Table 1. Genomic DNA obtained from whole blood samples was diluted at $1 \mathrm{ng} / \mathrm{\mu L}$ and $5.0 \mathrm{ng}$ was used for each $15 \mu \mathrm{L}$ real-time PCR using the TaqMan Master Mix (Applied Biosystems).

Statistical analysis was conducted using the Statistical Package for the Social Sciences (SPSS Inc., USA) and the STATA (Stata Corp., USA) software. Frequencies and percentages were used for categorical variables and means and standard deviations were calculated for continuous variables. Life tables were constructed for 1-, 3-, and 5-year survival according to anatomical site. Median follow-up was calculated for each site. Kaplan-Meier curves were constructed for each site and a log-rank test was used to compare these survival curves. At the end of follow-up, living patients, those dead from other cause (not head and neck cancer), and those lost during follow-up were considered censored.

Cox proportional hazards regression was used to estimate hazard ratios (HR) and the respective 95\% confidence intervals $(95 \% \mathrm{Cl})$ for disease-specific survival including education (classified into three strata), tobacco smoking (continuous variable according to consumption in pack-years), alcohol consumption (continuous variable according to $\mathrm{g}$ ethanol/day), and interleukin genetic polymorphisms according to specific subsite adjusted for age and gender.

\section{Results}

Patient characteristics are shown in Table 2. Most patients were diagnosed with oral/oropharynx cancer. Patient mean age was 56 years and males were predominant. Almost $70 \%$ of the patients had less than 5 years of

Table 2. Patient distribution by tumor anatomical site, social and demographic characteristics, tobacco smoking, alcohol consumption, tumor clinical stage, and genotypic frequencies of IL-2 and IL-6 polymorphisms.

\begin{tabular}{|c|c|c|}
\hline & Cases (total $=$ & 445) \\
\hline & $\mathrm{N}$ & $\%$ \\
\hline \multicolumn{3}{|l|}{ Anatomical site } \\
\hline Oral/oropharynx & 286 & 64.3 \\
\hline Hypopharynx & 54 & 12.1 \\
\hline Larynx & 105 & 23.6 \\
\hline \multicolumn{3}{|l|}{ Age (years) } \\
\hline$\leq 50$ & 143 & 32.1 \\
\hline $51-60$ & 154 & 34.6 \\
\hline $61-70$ & 111 & 24.9 \\
\hline$>70$ & 37 & 8.3 \\
\hline Mean (standard deviation) & $56.0(10.3)$ & \\
\hline \multicolumn{3}{|l|}{ Gender } \\
\hline Male & 390 & 87.6 \\
\hline Female & 55 & 12.4 \\
\hline \multicolumn{3}{|l|}{ Education (years) } \\
\hline$<1$ & 82 & 18.4 \\
\hline $1-4$ & 228 & 51.2 \\
\hline 5 or more & 135 & 30.3 \\
\hline \multicolumn{3}{|c|}{ Tobacco consumption (pack-years) } \\
\hline Mean (standard deviation) & $40.1(27.4)$ & \\
\hline \multicolumn{3}{|c|}{ Alcohol consumption (g ethanol/day) } \\
\hline Mean (standard deviation) & $147.8(182.3)$ & \\
\hline \multicolumn{3}{|l|}{ Clinical stage } \\
\hline CS III & 106 & 23.8 \\
\hline CS IV & 339 & 76.2 \\
\hline \multicolumn{3}{|l|}{$\mathrm{IL}-2+114^{\mathrm{a}}$} \\
\hline $\mathrm{G} / \mathrm{G}$ & 190 & 47.3 \\
\hline $\mathrm{G} / \mathrm{T}$ & 181 & 45.0 \\
\hline $\mathrm{T} / \mathrm{T}$ & 31 & 7.7 \\
\hline \multicolumn{3}{|l|}{ IL-2 -384b } \\
\hline $\mathrm{G} / \mathrm{G}$ & 66 & 16.1 \\
\hline $\mathrm{G} / \mathrm{T}$ & 159 & 38.7 \\
\hline $\mathrm{T} / \mathrm{T}$ & 186 & 45.3 \\
\hline \multicolumn{3}{|l|}{ IL-6 -174c } \\
\hline $\mathrm{G} / \mathrm{G}$ & 253 & 58.0 \\
\hline $\mathrm{G} / \mathrm{C}$ & 150 & 34.4 \\
\hline $\mathrm{C} / \mathrm{C}$ & 33 & 7.6 \\
\hline
\end{tabular}

a43 missing; b34 missing; c9 missing. 
schooling. Mean cumulative tobacco smoking was 40.1 pack-years and mean daily alcohol consumption was $147.8 \mathrm{~g}$ ethanol/day. Most cases were diagnosed at advanced tumor clinical stage (category CS IV). IL-2 +114 G/G, IL-2 -384 T/T, and IL-6 -174 G/G were the most common genotypes.

Table 3 shows post-diagnosis diseasespecific survival rates for the entire group of patients with overall HNSCC, and for specific subsites (oral cavity/oropharyngeal, hypopharyngeal and laryngeal cancer) at 1,3 , and 5 years. Figure 1 shows the survival curves for three HNSCC anatomical sites. Differences between the curves are clear (log-rank test, $P=0.001$ ). The best median survival time was observed for larynx tumors and the poorest for hypopharynx tumors.

Table 4 shows adjusted HR's for oral cavity/oropharynx, hypopharynx and larynx tumors according to education, tobacco smoking, alcohol consumption, IL-2 +114, IL-2 -384 , and IL-6 -174 adjusted for age and gender.

Higher education was positively associated with better survival for laryngeal cancer, but with poor survival for hypopharyngeal cancer. Tobacco smoking did not show any effect on survival in oral/oropharyngeal, hypopharyngeal, or laryngeal tumors.

$\mathrm{IL}-2+114 \mathrm{G} / \mathrm{T}$ and $\mathrm{T} / \mathrm{T}$ were associated with better prognosis in hypopharyngeal cancer. IL-2 -384 G/T showed better survival in oral cavity/oropharynx and hypopharynx tumors, but increased the risk of death in laryngeal cancer. IL-6 -174 C/C showed worse survival in oral cavity and hypopharyngeal cancer, but better survival in laryngeal cancer.

\section{Discussion}

Low socioeconomic status (SES) has been associated with the risk of head and neck cancer (29). The relationship between SES and disease prognosis is less well known. We observed different effects of educational levels on head and neck cancer, depending on tumor specific anatomical site. In oral cavity/oropharynx and hypopharyngeal tumors, the risk of death increased with more years of schooling, whereas in laryngeal cancer, it was associated with better survival. These results, however, were imprecise.

Tobacco smoking and alcohol consumption are wellknown risk factors for head and neck cancer, but the implications of these two factors in disease prognosis are not completely clear. Some studies have identified an effect, although not statistically significant, of these variables on head and neck cancer $(30,31)$. In our study, we observed that tobacco smoking had no effect on prognosis in oral cavity/oropharynx, hypopharynx, or laryngeal cancer. Alcohol consumption showed a statistically significant association with poor survival in laryngeal cancer, but the HR (consid-

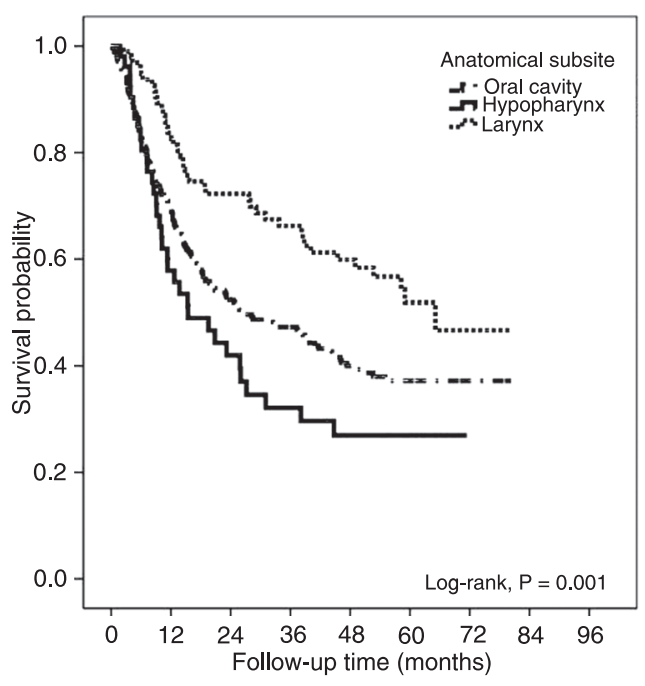

Figure 1. Survival of patients with head and neck squamous cell carcinoma related to specific anatomical sites: oral cavity, hypopharynx and larynx. Log-rank test for equality survival curves hypothesis (Kaplan-Meier or product limit estimator).

ering the increase of risk according to each g ethanol/day) was very close to 1 .

A statistically significant association was observed between high serum IL-2 levels and shorter survival time in head and neck cancer patients (32). In our study, we found that IL-2 +114 was associated with poor survival in oral cavity/oropharynx cancer, although amino acid sequence did not change (codon 38, CTG>CTT; Leu>Leu). Instead, this polymorphism was associated with increased survival in patients with hypopharyngeal tumors, while its effect was unclear in laryngeal cancer. The IL-2 polymorphism -384 T/T was associated with low survival in all anatomical subsites and has been reported to show lower IL-2 levels compared to the $\mathrm{G}$ allele, although there are many conflicting data showing opposite results, which indicate that other factors may contribute to the effect of this polymorphism on IL-2 expression levels (33).

Some studies have found an association between IL-6 
-174 genetic polymorphisms and the risk of prostate, colorectal, and lung tumors (15-17). Few studies have found IL-6 -174 as a worse prognostic factor in breast, bladder, and prostate cancer (20-22), principally with the presence of the $\mathrm{C}$ allele. In our study, IL-6 -174 G/C and G/G genotypes were associated with reduced mortality in patients with oral and hypopharynx cancer. Moreover, the same genotypes were associated with a better survival in larynx cancer. It has been reported that $\mathrm{G} / \mathrm{G}$ homozygotes produce higher levels of serum IL-6 when compared to $\mathrm{C} / \mathrm{G}$ heterozygotes or $\mathrm{C} / \mathrm{C}$ homozygotes (G/G>G/C>C/C) (34).

Some limitations of our study should be considered, such as sample size. Even though the total sample was relatively large, 445 , when tumors were stratified by anatomical origin, samples were reduced in size limiting the power of this study. Also, we were only able to genotype
IL-2 +114 and IL-2 -384 polymorphisms in 90.3 and $92.4 \%$ of our sample, respectively. This affects the precision of our results, especially those related to genetic polymorphisms. A second possible limitation that we should not ignore was related to human papillomavirus (HPV). The presence of HPV infection may alter tumor profile and could have some implications in outcome. Individuals with HPV infection appear to have increased survival in oral cancer, but the reasons for this are unclear $(35,36)$. A recent study on a group of patients enrolled in a randomized clinical trial has suggested an association with HPV-positivity as an independent prognostic factor among patients with oropharyngeal cancer (37). Moreover, in a recent report, the anti-apoptotic effect of HPV E6 expression was found to be mediated in part by up-regulation of osteoprotegerin and IL-6 in cutaneous squamous cell carcinoma (38). In a

Table 4. Cox proportional hazards model for disease-specific survival according to the study variables.

\begin{tabular}{|c|c|c|c|}
\hline Variable & $\begin{array}{l}\text { Oral cavity/oropharyngeal } \\
\text { [adjusted HR (95\%Cl); P] }\end{array}$ & $\begin{array}{c}\text { Hypopharyngeal } \\
\text { [adjusted HR }(95 \% \mathrm{Cl}) ; \mathrm{P} \text { ] }\end{array}$ & $\begin{array}{c}\text { Laryngeal } \\
\text { [adjusted HR }(95 \% \mathrm{Cl}) ; \mathrm{P} \text { ] }\end{array}$ \\
\hline \multicolumn{4}{|l|}{ Age (years) } \\
\hline$\leq 50$ & 1.00 & 1.00 & 1.00 \\
\hline $51-60$ & 1.03 (0.66-1.61); 0.88 & 1.09 (0.24-4.90); 0.91 & $0.63(0.22-1.81) ; 0.39$ \\
\hline $61-70$ & $1.34(0.78-2.31) ; 0.28$ & 2.00 (0.33-12.04); 0.46 & $1.22(0.44-3.35) ; 0.71$ \\
\hline$>70$ & 1.40 (0.61-3.20); 0.42 & 13.09 (1.37-125.12); 0.03 & 1.03 (0.22-4.79); 0.97 \\
\hline \multicolumn{4}{|l|}{ Gender } \\
\hline Female & 1.00 & NA & 1.00 \\
\hline Male & $1.19(0.66-2.14) ; 0.57$ & & 2.50 (0.45-13.85); 0.29 \\
\hline \multicolumn{4}{|l|}{ Education (years) } \\
\hline$<1$ & 1.00 & 1.00 & 1.00 \\
\hline $1-4$ & 1.10 (0.63-1.93); 0.74 & $2.44(0.53-11.20) ; 0.25$ & $0.70(0.22-2.24) ; 0.55$ \\
\hline$\geq 5$ & $1.16(0.61-2.20) ; 0.64$ & $4.86(0.56-42.30) ; 0.15$ & 0.39 (0.10-1.53); 0.18 \\
\hline \multicolumn{4}{|l|}{ Smokinga } \\
\hline Pack-years & 1.00 (0.99-1.01); 0.51 & $1.00(0.97-1.01) ; 0.45$ & $1.00(0.98-1.01) ; 0.41$ \\
\hline \multicolumn{4}{|c|}{ Alcohol consumption ${ }^{\mathrm{b}}$} \\
\hline g ethanol/day & 1.00 (0.99-1.00); 0.87 & 1.00 (0.99-1.00); 0.78 & $1.00(1.00-1.01) ; 0.01$ \\
\hline \multicolumn{4}{|l|}{ IL-2 +114 } \\
\hline $\mathrm{G} / \mathrm{G}$ & 1.00 & 1.00 & 1.00 \\
\hline $\mathrm{G} / \mathrm{T}$ & 1.07 (0.72-1.57); 0.75 & $0.52(0.15-1.81) ; 0.31$ & 1.32 (0.61-2.85); 0.48 \\
\hline $\mathrm{T} / \mathrm{T}$ & $1.14(0.58-2.23) ; 0.70$ & $0.22(0.02-3.19) ; 0.27$ & $0.86(0.15-4.80) ; 0.86$ \\
\hline \multicolumn{4}{|l|}{ IL-2 -384 } \\
\hline $\mathrm{G} / \mathrm{G}$ & 1.00 & 1.00 & 1.00 \\
\hline $\mathrm{G} / \mathrm{T}$ & $0.80(0.45-1.42) ; 0.45$ & $0.68(0.21-2.20) ; 0.52$ & 2.42 (0.71-8.30); 0.16 \\
\hline $\mathrm{T} / \mathrm{T}$ & 1.11 (0.64-1.93); 0.71 & 1.95 (0.52-7.37); 0.32 & $1.32(0.39-4.47) ; 0.66$ \\
\hline \multicolumn{4}{|l|}{ IL-6 -174 } \\
\hline $\mathrm{G} / \mathrm{G}$ & 1.00 & 1.00 & 1.00 \\
\hline $\mathrm{G} / \mathrm{C}$ & 1.00 (0.68-1.49); 0.99 & 0.68 (0.26-1.78); 0.43 & $0.93(0.42-2.07) ; 0.86$ \\
\hline $\mathrm{C} / \mathrm{C}$ & 1.23 (0.69-2.18); 0.48 & 3.33 (0.51-23.01); 0.21 & $0.12(0.01-1.52) ; 0.10$ \\
\hline
\end{tabular}

$\mathrm{HR}=$ hazard ratio $; 95 \% \mathrm{Cl}=95 \%$ confidence interval; $\mathrm{NA}=$ not available; apack-years = number of cigarette packs smoked per day versus number of years of smoking; HR calculated for each pack-year increase. bHR calculated for each $\mathrm{g}$ ethanol/day increase. 
case-control study on women with cervical neoplasias, the authors showed that the level of E7-induced IL-2 production from the lymphocytes of patients with HPV 16 clearance was inversely correlated with the time relative to the last HPV DNA + test (39). In another study on women with cervical and vulvar cancer, the results suggested an increased risk of cancer among smokers modified by genetic variation in IL-2, cigarette components and decreased IL-2 levels (40). Confounding effects from tobacco use and tumor clinical stage at diagnosis have not been ruled out as potential reasons for the association between HPV and survival. In addition, we assumed that treatment was similar for all patients with head and neck cancer, but this could be an important confounding variable in studies on cancer

\section{References}

1. Ferlay J, Shin HR, Bray F, Forman D, Mathers C, Parkin DM. GLOBOCAN 2008, Cancer incidence and mortality worldwide: IARC CancerBase No. 10. http://globocan.iarc.fr.

2. Instituto Nacional de Câncer (INCA). Coordenação de prevenção e vigilância de câncer. Secretaria de Atenção à Saúde. Ministério da Saúde. Estimativas 2008. Incidência de câncer no Brasil. Rio de Janeiro: INCA; 2007.

3. Stewart BW, Kleihues P. World cancer report. Lyon: IARC Press; 2003.

4. Carvalho AL, Ikeda MK, Magrin J, Kowalski LP. Trends of oral and oropharyngeal cancer survival over five decades in 3267 patients treated in a single institution. Oral Oncol 2004; 40: 71-76.

5. de Graeff A, de Leeuw Jr, Ros WJ, Hordijk GJ, Blijham GH, Winnubst JA. Sociodemographic factors and quality of life as prognostic indicators in head and neck cancer. Eur J Cancer 2001; 37: 332-339.

6. Teppo H, Alho OP. Comorbidity and diagnostic delay in cancer of the larynx, tongue and pharynx. Oral Oncol 2009; 45: 692-695.

7. Dikshit RP, Boffetta P, Bouchardy C, Merletti F, Crosignani $\mathrm{P}$, Cuchi T, et al. Lifestyle habits as prognostic factors in survival of laryngeal and hypopharyngeal cancer: a multicentric European study. Int J Cancer 2005; 117: 992-995.

8. Chiang YY, Tsai MH, Lin TY, Chiang IP. Expression profile of metastasis-related genes in invasive oral cancers. Histol Histopathol 2008; 23: 1213-1222.

9. Shimizu Y, Kondo S, Shirai A, Furukawa M, Yoshizaki T. A single nucleotide polymorphism in the matrix metalloproteinase- 1 and interleukin- 8 gene promoter predicts poor prognosis in tongue cancer. Auris Nasus Larynx 2008; 35: 381-389.

10. Hopkins J, Cescon DW, Tse D, Bradbury P, Xu W, Ma C, et al. Genetic polymorphisms and head and neck cancer outcomes: a review. Cancer Epidemiol Biomarkers Prev 2008; 17: 490-499.

11. Serefoglou Z, Yapijakis C, Nkenke E, Vairaktaris E. Genetic association of cytokine DNA polymorphisms with head and neck cancer. Oral Oncol 2008; 44: 1093-1099.

12. Tartour E, Mosseri V, Jouffroy T, Deneux L, Jaulerry C, Brunin F, et al. Serum soluble interleukin-2 receptor concen- survival. These limitations argue the case for a prudent interpretation of our results.

Overall, our study revealed the same inconsistent results as some earlier reports on the prognostic value of environmental factors, such as education, tobacco smoking, and alcohol consumption, as well as IL-2 and IL-6 gene polymorphisms in HNSCC.

\section{Acknowledgments}

Research supported by FAPESP (\#2001/01768-2 and \#2005/50832-6) and the European Commission (\#IC18CT97-022).

trations as an independent prognostic marker in head and neck cancer. Lancet 2001; 357: 1263-1264.

13. Wu HC, Chang CH, Wan L, Wu Cl, Tsai FJ, Chen WC. IL-2 gene $\mathrm{C} / \mathrm{T}$ polymorphism is associated with prostate cancer. J Clin Lab Anal 2006; 20: 245-249.

14. Wu J, Lu Y, Ding YB, Ke Q, Hu ZB, Yan ZG, et al. Promoter polymorphisms of IL-2, IL4, and risk of gastric cancer in a high-risk Chinese population. Mol Carcinog 2009; 48: 626632.

15. Ennas MG, Moore PS, Zucca M, Angelucci E, Cabras MG, Melis M, et al. Interleukin-1B (IL1B) and interleukin-6 (IL-6) gene polymorphisms are associated with risk of chronic lymphocytic leukaemia. Hematol Oncol 2008; 26: 98-103.

16. Belluco C, Olivieri F, Bonafe M, Giovagnetti S, Mammano E, Scalerta R, et al. $-174 \mathrm{G}>\mathrm{C}$ polymorphism of interleukin 6 gene promoter affects interleukin 6 serum level in patients with colorectal cancer. Clin Cancer Res 2003; 9: 21732176.

17. Colakogullari M, Ulukaya E, Yilmaztepe OA, Aymak F, Basturk B, Ursavas A, et al. The involvement of IL-10, IL-6, IFN-gamma, TNF-alpha and TGF-beta gene polymorphisms among Turkish lung cancer patients. Cell Biochem Funct 2008; 26: 283-290.

18. Vairaktaris E, Yapijakis C, Serefoglou Z, Avgoustidis D, Critselis E, Spyridonidou S, et al. Gene expression polymorphisms of interleukins- 1 beta, $-4,-6,-8,-10$, and tumor necrosis factors-alpha, -beta: regression analysis of their effect upon oral squamous cell carcinoma. $J$ Cancer Res Clin Oncol 2008; 134: 821-832.

19. Savage SA, Abnet CC, Haque K, Mark SD, Qiao YL, Dong $\mathrm{ZW}$, et al. Polymorphisms in interleukin-2, -6 , and -10 are not associated with gastric cardia or esophageal cancer in a high-risk Chinese population. Cancer Epidemiol Biomarkers Prev 2004; 13: 1547-1549.

20. DeMichele A, Gray R, Horn M, Chen J, Aplenc R, Vaughan WP, et al. Host genetic variants in the interleukin- 6 promoter predict poor outcome in patients with estrogen receptorpositive, node-positive breast cancer. Cancer Res 2009; 69: 4184-4191.

21. Leibovici D, Grossman HB, Dinney CP, Millikan RE, Lerner $S$, Wang $Y$, et al. Polymorphisms in inflammation genes and 
bladder cancer: from initiation to recurrence, progression, and survival. J Clin Oncol 2005; 23: 5746-5756.

22. Pierce BL, Biggs ML, DeCambre M, Reiner AP, Li C, Fitzpatrick $A$, et al. C-reactive protein, interleukin-6, and prostate cancer risk in men aged 65 years and older. Cancer Causes Control 2009; 20: 1193-1203.

23. World Health Organization. International statistical classification of diseases and related health problems. 10th revision. Geneva: World Health Organization; 2004.

24. Hashibe M, Brennan P, Benhamou S, Castellsague X, Chen $C$, Curado MP, et al. Alcohol drinking in never users of tobacco, cigarette smoking in never drinkers, and the risk of head and neck cancer: pooled analysis in the International Head and Neck Cancer Epidemiology Consortium. J Natl Cancer Inst 2007; 99: 777-789.

25. American Joint Committee on Cancer. AJCC staging manual for cancer. 5th edn. Philadelphia: Lippincott-Raven; 1997.

26. International Agency for Research on Cancer (IARC). Tobacco smoking. IARC Monogr 36. Lyon: IARC Press; 1986.

27. International Agency for Research on Cancer (IARC). Alcohol drinking. IARC Monogr 33. Lyon: IARC Press; 1988.

28. De La Vega FM, Lazaruk KD, Rhodes MD, Wenz MH. Assessment of two flexible and compatible SNP genotyping platforms: TaqMan SNP Genotyping Assays and the SNPlex Genotyping System. Mutat Res 2005; 573: 111-135.

29. Conway DI, Petticrew M, Marlborough H, Berthiller J, Hashibe M, Macpherson LM. Socioeconomic inequalities and oral cancer risk: a systematic review and meta-analysis of casecontrol studies. Int J Cancer 2008; 122: 2811-2819.

30. Nguyen-Tan PF, Le QT, Quivey JM, Singer M, Terris DJ, Goffinet DR, et al. Treatment results and prognostic factors of advanced T3-4 laryngeal carcinoma: the University of California, San Francisco (UCSF) and Stanford University Hospital (SUH) experience. Int J Radiat Oncol Biol Phys 2001; 50: 1172-1180.

31. Boffetta P, Merletti F, Faggiano F, Migliaretti G, Ferro G, Zanetti $R$, et al. Prognostic factors and survival of laryngeal cancer patients from Turin, Italy. A population-based study. Am J Epidemiol 1997; 145: 1100-1105.
32. El Houda Agueznay N, Badoual C, Hans S, Gey A, Vingert $B$, Peyrard S, et al. Soluble interleukin-2 receptor and metalloproteinase- 9 expression in head and neck cancer: prognostic value and analysis of their relationships. Clin Exp Immunol 2007; 150: 114-123.

33. Vandenbroeck K. Cytokine gene polymorphisms in multifactorial conditions. Boca Raton: CRC Press; 2006.

34. Lagmay JP, London WB, Gross TG, Termuhlen A, Sullivan N, Axel A, et al. Prognostic significance of interleukin- 6 single nucleotide polymorphism genotypes in neuroblastoma: rs1800795 (promoter) and rs8192284 (receptor). Clin Cancer Res 2009; 15: 5234-5239.

35. Fakhry C, Westra WH, Li S, Cmelak A, Ridge JA, Pinto H, et al. Improved survival of patients with human papillomavirus-positive head and neck squamous cell carcinoma in a prospective clinical trial. J Natl Cancer Inst 2008; 100: 261269.

36. Smith EM, Wang D, Rubenstein LM, Morris WA, Turek LP, Haugen TH. Association between p53 and human papillomavirus in head and neck cancer survival. Cancer Epidemiol Biomarkers Prev 2008; 17: 421-427.

37. Ang KK, Harris J, Wheeler R, Weber R, Rosenthal DI, Nguyen-Tan PF, et al. Human papillomavirus and survival of patients with oropharyngeal cancer. N Engl J Med 2010; 363: 24-35.

38. Tomlins C, Storey A. Cutaneous HPV5 E6 causes increased expression of Osteoprotegerin and Interleukin 6 which contribute to evasion of UV-induced apoptosis. Carcinogenesis 2010; 31: 2155-2164.

39. de Gruijl TD, Bontkes HJ, Walboomers JM, Stukart MJ, Doekhie FS, Remmink AJ, et al. Differential T helper cell responses to human papillomavirus type $16 \mathrm{E} 7$ related to viral clearance or persistence in patients with cervical neoplasia: a longitudinal study. Cancer Res 1998; 58: 1700-1706.

40. Hussain SK, Madeleine MM, Johnson LG, Du Q, Malkki $\mathrm{M}$, Wilkerson HW, et al. Cervical and vulvar cancer risk in relation to the joint effects of cigarette smoking and genetic variation in interleukin 2. Cancer Epidemiol Biomarkers Prev 2008; 17: 1790-1799. 